\title{
Memórias 2000
}

Last year the Memórias do Instituto Oswaldo Cruz celebrated 90 years of continuous publication and at a workshop, held in commemoration by the Brazilian Association of Scientific Editors, participants were able to learn many aspects of its history and current progress. Recently, citation data for 1999 have been released by the Institute of Scientific Information of Philadelphia, PA, USA (Journal Citation Reports 1999). The data show a continued increase in the impact factor and total citations. These indices were more than one third higher for 1999 as compared to 1998 and show an improvement of nearly $150 \%$ in the last five years (Figure). The Memórias is now the Brazilian periodical with the highest impact factor and the most highly cited journal published in Latin America. The increase in manuscript submissions received in 2000 is probably a consequence of its increasing recognition as an international journal published in Brazil.
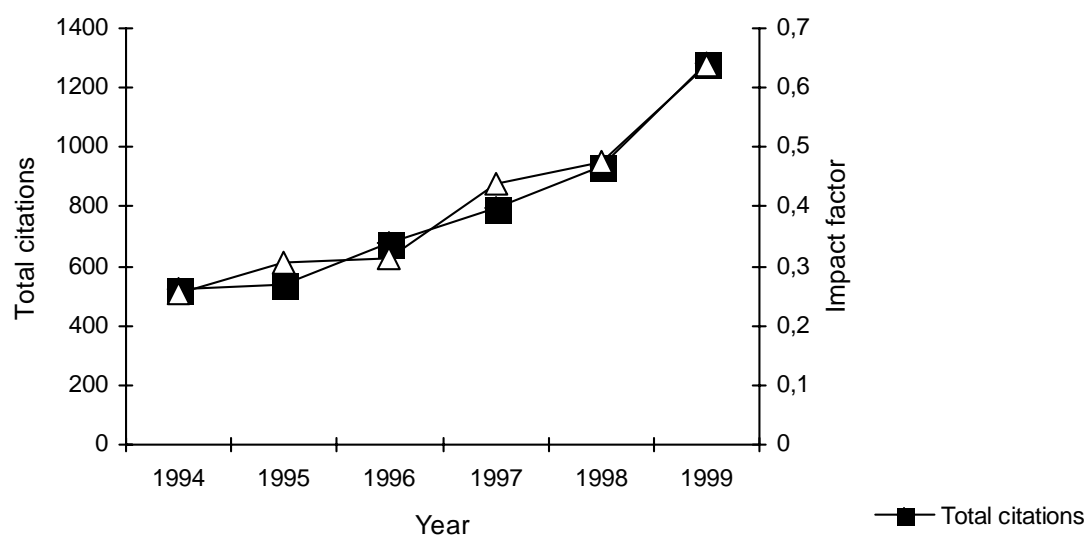

$\triangle-$ Impact factor

Source: Institute of Scientific Information of Philadelphia

Further increase in the quality of the periodical will only come from capturing part of the top quality manuscripts that local scientists invariably send to the most highly cited international journals. The task of persuading the best scientists to publish locally comes at a time when technological changes are rapidly changing the nature of scholarly publishing. At a recent meeting of the International Federation of Scientific Editors (IFSE) held in Rio de Janeiro some of the challenges presented by the new technologies were presented (http://www.bireme.br/ifse). In particular electronic publishing and the internet are providing opportunities for regional journals to compete more efficiently.

The decision by Carlos Chagas to publish his discovery of American trypanosomiasis in the first volume of the Memórias, as well as important studies by other scientists of the "Escola de Manguinhos", was fundamental in establishing the reputation of the journal. Chagas could have published his manuscript in an European journal as he did with other articles but decided to publish his great discovery, that was later considered for the Nobel prize, in the Memórias. The article by Chagas has been regularly cited ever since and continues to be cited even today.

Can we again persuade top scientists to publish their best manuscripts in the Memórias? The answer to this question depends, in part, on understanding what authors want from a good academic journal. Among the reasons that scientist seek top journals for their work is to obtain visibility. They want manuscript to be seen by the widest audience of fellow workers. Another reason is credibility. Authors seek, for their articles, journals with rigorous peer review that will provide quality control and certification of their results. Additional reasons include speed of publication and the prestige of publishing in a highly ranked international journal.

What can the Memórias offer in these respects? In terms of visibility, the Memórias is now available in on-line and print formats, while selected volumes are also on CD-ROM. The decision has been made to give free access to the on-line version in both HTML and PDF formats. Through the SciELO project (http://www.scielo.br) these articles are currently linked to their corresponding abstracts in Medline and 
hopefully soon in other databases such as Web of Science. This combination has given an unprecedented visibility to the Memórias articles and may be an important reason for the increase in citation rates.

Improvements in peer review and time to publication are the challenges ahead. Beginning in 2001 the Journal will increase from six to eight the number of issues that are published each year. This should result in an improvement in the time from acceptance to publication of manuscripts. The period from submission to acceptance is associated with the peer review process. In this the Memórias will continue to depend on the collaboration and expertise of its unpaid referees. During the next year a statement will be prepared and published describing clearly, for potential authors, the procedures for peer review in the journal. Among the efforts to improve the peer review process will be the planning of experiments with some manuscripts, using open reviewing (author and referees known to each other) and electronic submission of manuscripts for reviewing.

There is a movement to give authors greater control over the intellectual property rights of their work including the self-archiving of preprints and post-publication articles on their own or institution's computer servers. The Memórias is sensitive to these concerns and will, in the near future, amend its copyright forms to allow those authors, who desire to, the right to self-archive their articles.

Finally a journal can only increase its international prestige by giving a further impulse to the virtuous circle of quality manuscripts improving the impact and citations of the journal that in turn attract higher quality manuscripts and highly cited authors. In this respect we would encourage authors to consider sending their best manuscripts for review to the Memórias. 